\title{
Socioeconomic status and glycemic index among punjabis in Kuala Lumpur, Malaysia: possible association with metabolic syndrome
}

\begin{abstract}
There are only limited reports on Punjabi's health status in Malaysia. This cross-sectional study assessed the prevalence of metabolic syndrome (Mets) and its risk factors among 277 subjects recruited from the Malaysian Punjabi community. Overall prevalence of Mets was 43\%, but $61 \%$ among females. Subjects classified with Mets had significantly $(\mathrm{p}<0.05)$ higher body mass index, visceral fat and percentage of body fat. Daily carbohydrate and glycemic index (GI) were also higher among Mets subjects $(\mathrm{p}<0.05)$. Logistics regression analysis showed that primary level of education (OR 5.57, CI 1.29-23.97, $\mathrm{p}=0.021)$ was a factor associated with Mets, followed by middle household income (OR 2.30, CI 1.01-5.20, p =0.046), GI (OR 1.03, CI 1.00-1.06, $\mathrm{p}=0.026$ ), and age (OR 1.03, CI 1.00-1.05, $\mathrm{p}=0.023$ ). Mets shows high prevalence among the studied Punjabi population, prompting the consideration of adequate preventive measures, primarily among lower socioeconomic groups.
\end{abstract}

Keyword: Punjabi; Malaysia; Metabolic syndrome; Glycemic index; Socioeconomic status 